\title{
Por Uma Reflexão Sociológica Acerca da Racionalidade Neoliberal
}

Submetido em: $20 / 10 / 2020$, aprovado em: 08/12/2020

10.30612/mvt.v7i13.12846

Kleiton Wagner Alves da Silva Nogueira'

RESUMO: O presente artigo objetiva realizar uma reflexão inicial sobre as categorias de racionalidade e dominação através do Neoliberalismo como fenômeno político, social e econômico. Sendo uma pesquisa de cunho bibliográfico, a reflexão foi embasada nos conceitos de dominaçáo e racionalidade legal de Max Weber e no declínio vocacional de George Simmel. Procura-se também, inserir os estudos dos sociólogos franceses Christian Laval e Françoa Dardot sobre a racionalidade neoliberal contemporânea. Dessa forma, o artigo está dividido em três partes: a) Racionalidade e dominação: o desprendimento de si na modernidade; b) Um debate acerca do Neoliberalismo: uma nova "racionalidade" do ser? c) A neutralidade do gerencialismo na administração pública; além da introdução e considerações finais. Como principais elementos do nosso estudo, salientamos o elemento aparentemente neutro sob o qual o neoliberalismo coloniza as administraçóes estatais perante o prisma do gerencialismo, o que evidencia a necessidade de pesquisas empíricas sobre a temática.

Palavras-chave: Estado. Neoliberalismo. Dominação. Racionalidade. Administração Pública.

\section{Towards a sociological reflection on neoliberal rationality}

ABSTRACT: This article aims to make an initial reflection on the categories of rationality and domination through neoliberalism as a political, social and economic phenomenon. As a bibliographical research, the reflection was based on the concepts of domination and legal rationality of Max Weber and the vocational decline of George Simmel. It also seeks to insert the studies of French sociologists Christian Laval and Françoa Dardot on contemporary neoliberal rationality. Thus, the article is divided into three parts: a) Rationality and domination: selflessness in modernity; b) A debate about neoliberalism: a new "rationality" of being? c) The neutrality of managerialism in public administration; beyond the introduction and final considerations. As main elements of our study, we highlight the apparently neutral element under which neoliberalism colonizes state administrations from the perspective of managerialism, which highlights the need for empirical

1 Licenciado em Geografia pela Universidade Federal de Campina Grande (UFCG), Bacharel em Administração pela Universidade Estadual da Paraíba (UEPB); Mestrando pelo Programa de Pós-Graduação em Ciências Sociais da UFCG. Integrante do Grupo de Estudos e Pesquisas sobre Estado e Luta de Classes na América Latina (PRÁXIS/UFCG). E-mail: kleiton_wagner@hotmail.com 
research on the subject.

Keywords: State. Neoliberalism. Domination. Rationality. Public administration.

\section{Para una reflexión sociológica sobre la racionalidad neoliberal}

RESUMEN: Este artículo tiene como objetivo hacer una reflexión inicial sobre las categorías de racionalidad y dominación a través del neoliberalismo como fenómeno político, social y económico. Como investigación bibliográfica, la reflexión se basó en los conceptos de dominación y racionalidad jurídica de Max Weber y el declive vocacional de George Simmel. También busca insertar los estudios de los sociólogos franceses Christian Laval y Françoa Dardot sobre la racionalidad neoliberal contemporánea. Así, el artículo se divide en tres partes: a) Racionalidad y dominación: desinterés en la modernidad; b) Un debate sobre el neoliberalismo: ¿una nueva "racionalidad" del ser? c) La neutralidad del gerencialismo en la administración pública; más allá de la introducción y las consideraciones finales. Como elementos principales de nuestro estudio, destacamos el elemento aparentemente neutral bajo el cual el neoliberalismo coloniza las administraciones estatales desde la perspectiva del gerencialismo, lo que resalta la necesidad de una investigación empírica sobre el tema.

Palavras Clave: Estado Neoliberalismo Dominación Racionalidad. Administracion publica.

\section{INTRODUÇÃO}

O indivíduo em sua subjetividade ressignifica as relaçóes que vivencia através da perspectiva da experiência material. As grandes cidades, por exemplo, são locais em que o limite entre a subjetividade e a objetividade humana demarcam essa dualidade num movimento dialético, tendo em vista a grandeza monumental de seus sistemas de engenharia, composições arquitetônicas, relaçóes afetivas e materiais. O ethos da grande cidade é o do mundo moderno capitalista em conformidade com o frenesi das relaçóes cotidianas, a multidão de olhares, os contatos, as relaçôes efêmeras, moldando assim, a forma de sociabilidade que temos que construir. É nessa contradição entre o estar inserido em fluxos agitados ao mesmo tempo em que procuramos refúgio em locais próprios, topofílicos e repletos de significados que entendemos o valor e a força da racionalidade humana.

Podemos pensar conforme destaca Weber (2014), no tocante aos elementos da racionalidade burocrática de matriz legal, que estas promovem um choque de intersubjetividades, de elementos contraditórios e complementares na vida dos indivíduos. Nesse caso, a vida moderna insere a perspectiva da impessoalidade nas relaçôes, da objetividade e da contabilidade neurótica dos elementos da vida. De indivíduos, passamos a ser números, resultados, diplomas e certificaçóes de habilidades e competências para o mercado, instituição que Simmel ([1903] 2005) reflete por munir a sociedade de uma economia monetária para além dos aspectos meramente econômicos.

É dentro desse limiar que enxergamos o elo entre racionalidade capitalista e a perspectiva da autodeterminação. Assim como Weber ([1905] 2013) mostrou uma pré-destinação oriunda do 
calvinismo no despojamento do divino, refletimos que na contemporaneidade somos predestinados a comparabilidades e ao mundo da concorrência como o mais novo encantamento com o mundo, que mina instituiçôes, grupos, relações e o próprio capitalismo. Numa sociedade que possui fetiche deliberado por números, nossos relacionamentos são baseados em índices, currículos e na posse de bens simbólicos para além dos aspectos meramente econômicos, mesmo este sendo condição sine qua non em nosso entendimento para a aquisição de cultura, tendo em vista que, partimos do pressuposto da condicionalidade dos elementos ideológicos da vida pela esfera material.

Contudo, para além das preocupaçôes de Max Weber relacionadas ao domínio da burocracia - "malha de aço" - que molda o domínio da vida dos indivíduos, problematizamos nesse artigo como a nova roupagem racional, com base na visáo de Dardot e Laval ([2009] 2017) implica em uma estrutura dita "pós-weberiana" materializada em uma nova razão do mundo marcada em especial pelo domínio da concorrência levado a cabo pela tônica do gerencialismo, que sublima a luta de classes e pautas sociais, reduzindo todos os problemas e estruturas ao elemento da gestáo e da gerência. Dentro dessa perspectiva, pretendemos com o presente artigo realizar uma reflexão inicial sobre as categorias de racionalidade e dominação através do Neoliberalismo enquanto uma ideologia que, para além dos elementos econômicos, influencia sobremaneira na esfera individual.

Nesse sentido, iniciamos nosso percurso pelo debate acerca da racionalidade moderna tomando como base Max Weber, de modo a associar essa racionalidade à dominação racional legal e a burocracia como categoria central em torno do desprendimento de si e da abertura aos valores das instituiçóes modernas. Em seguida, introduzimos a reflexão em torno de uma "nova razão do mundo", com base nos sociólogos franceses Christian Laval e Françoa Dardot, por considerarmos que nesses autores é possível encontrar a categoria de "neogestão" na relação entre Estado, sociedade e indivíduo. Em um terceiro momento, buscamos explorar como o Neoliberalismo através do gerencialismo reproduz uma lógica concorrencial na administração estatal. Por fim, nas consideraçóes finais lançamos mão de elementos que nos permitem realizar novos apontamentos sobre a problemática colocada no artigo, assim como questionamentos sobre os desdobramentos de nossa reflexáo para uma análise empírica de maior fôlego.

\section{RACIONALIDADE E DOMINAÇÃO: O DESPRENDIMENTO DE SI NA MODERNIDADE}

Ao passo que o desenvolvimento da ciência torna-se instrumento na manipulação e transformação da natureza, técnica e racionalidade tornam-se léxicos comuns de uma ordem societal. Desde os primórdios da humanidade as necessidades vinculadas à sobrevivência diante de uma primeira natureza "bruta" fizeram com que o ser humano em seu constante relacionamento com o meio natural, formulasse técnicas para o beneficiamento da vida frente aos grandes mistérios da natureza. Em um primeiro momento podemos até considerar que a natureza implicasse em um grande desconhecido, sendo tema para os mais variados mitos, lendas e explicaçóes metafísicas. Contudo, com o passar do tempo e em especial com o advento da modernidade através da ascensão da era industrial, observamos uma clivagem importante no modo como os seres humanos passam a se organizar em sociedade.

A passagem de explicaçóes de ordem sobrenatural para um "desencantamento com o mundo" implicou numa reviravolta no modo de relação entre homem e natureza. A esse modo, o ser humano passa a enfrentar a natureza não mais como uma entidade desconhecida, mas como um meio de 
produção a ser explorado e utilizado em benefício do desenvolvimento econômico e social. Podemos considerar em Max uma importante reflexão em torno desse debate, tendo em vista que esse autor trouxe grandes contribuiçóes às Ciências Sociais ao teorizar sobre o surgimento do capitalismo a partir de uma perspectiva sociológica.

Em seu ensaio: A ética protestante e o espirito capitalista, publicado no início do século XX, esse autor mostra como elementos de ordem social influenciaram no surgimento de um tipo específico de ética que juntamente com o capitalismo, formaram o par perfeito de uma nova racionalidade da era moderna. Ao realizar um aprofundado estudo de matriz sociológica, utilizando como método a comparação e diferenciação entre os mais variados elementos religiosos, conclui que é no calvinismo que podemos encontrar um ethos racional do capitalismo que possui como gênese a esfera vocacional do trabalho necessária para o tipo de racionalidade associada ao desenvolvimento do modo de produção capitalista.

Cabe destacar que, mesmo diante das diferenças epistemológicas entre Marx e Weber, este considerou para além das distorçóes demagógicas que muitos deram ao pensamento de Marx que a relação entre estrutura e superestrutura, no modo de produção capitalista eram instâncias necessárias ao entendimento do capitalismo. Entretanto, podemos reconhecer que Weber ([1905] 2013) empreendeu outra perspectiva teórico-metodológica para a explicação do surgimento do capitalismo em comparaçáo aos estudos de Marx.

Dessa forma, ao dar primazia à produção intelectual ocidental, Weber encontra uma cadeia lógica de elementos que ele utilizaria para defender a tese de uma ética protestante do espírito capitalista. Ao tratar do capitalismo enquanto modo de produção, esse autor salienta como característica essencial o constante movimento de renovação do lucro de forma racional. A racionalidade seria condição fundamental para a modelagem e constituição do capitalismo como um sistema social. A obtenção de lucro através de meios pacíficos de troca e pelo trabalho livre formariam um mercado de trocas que inaugurou a separação entre pessoa física e pessoa jurídica, condição necessária na formação do mercado capitalista contemporâneo. Por conseguinte, o surgimento do capitalismo só foi possível devido à centralidade exercida pela organização racional do trabalho, pelo cálculo exato do trabalho livre e desenvolvimento de técnicas associadas a uma racionalidade instrumental. Esse cálculo racional dos fatores técnicos seria a influência da ciência moderna que, segundo Weber ([1905] 2013) receberia grande estímulo do modo de produção capitalista, tendo em vista que o desenvolvimento da técnica foi bastante utilizado em aplicaçôes econômicas.A utilização da técnica e do conhecimento científico são elementos necessários para a racionalização dos recursos, além de estabelecer uma ordem social constituída em princípios legais, Weber ([1917] 2014) entende que a moderna empresa capitalista está baseada no cálculo, em uma necessidade de justiça e administraçôes funcionais.

É importante refletirmos a respeito de como essa racionalidade inunda a vida cotidiana dos indivíduos e, de certa maneira, guia a vida dos sujeitos do nascimento até a morte. Caso contrário, daremos a entender que os escritos de Weber sobre racionalidade refletem apenas um caráter descritivo e acrítico, o que não é verdade, tendo em vista que ao realizar uma investigação sobre o modo de dominação presente na sociedade, Weber (2014) considera basicamente três tipos ou sistemas de dominação: tradicional, carismático e racional legal. Iremos focar no último exemplo citado, por considerarmos ser mais presente e aplicado a reflexão iniciada nesse artigo.

A dominação racional legal teria como sustentação os princípios legais do direito que através 
da figura Estatal com seu monopólio do uso da violência programou uma sociabilidade marcada - podemos dizer - por estatutos, leis e normas. Para além da empresa capitalista, julgamos essas características como fatores presentes no cotidiano dos indivíduos através das organizaçóes, que em si mesmas, seguem princípios legais. Doravante, Weber ([1917] 2014) considera que sob a batuta da burocracia teríamos o tipo mais ideal de dominaçáo legal racional. A burocracia reuniria características necessárias aos empreendimentos do Estado capitalista - e não apenas no capitalismo, mas também no socialismo conforme aponta Bresser Pereira (2004) e como demonstrou a história através da burocracia stalinista na extinta União Soviética - de forma a contemplar três principais pilares: Sistema jurídico de leis e normas para o ordenamento administrativo; divisão de tarefas e autoridade emanada de ordens com base em uma estrutura legal. Esses três elementos estariam presentes tanto em âmbito público, quanto no privado:

Estes três elementos constituem, no governo público - e legal, a "autoridade burocrática". No âmbito econômico privado fazem parte da "administração" burocrática. [...] a burocracia somente está totalmente desenvolvida nas comunidades políticas e eclesiásticas do Estado moderno; no caso da economia privada somente o está nas instituiçóes capitalistas mais avançadas (WEBER, 2014, p. 09).

De modo a demandar uma racionalidade impessoal, precisa e objetiva, ao colocar a organização empresarial como o primado da eficiência e eficácia, constata-se a importância do assujeitamento dos indivíduos a determinadas regras estabelecidas pela burocracia e, para além desse fator, evidencia-se também um desprendimento de si relacionado à esfera do trabalho. Tendo em vista que a separabilidade entre esfera privada e profissional é um dos elementos essenciais da burocracia. Esse desprendimento de si não implica em uma total passividade do indivíduo frente aos elementos oníricos da vida. Pelo contrário, mostra uma forma de encaixe a uma determinada realidade imposta como meio de sociabilidade geral, que prende os sujeitos em uma "malha de aço" ao permitir náo uma fuga da burocracia, mas certa maleabilidade frente a esse tipo de dominação.

A respeito dessa forma de maleabilidade frente aos itinerários da racionalidade moderna, encontramos em Simmel ([1903] 2005) uma importante reflexão sobre a sociabilidade nas grandes cidades modernas que passaram a surgir com o advento da industrialização. Esses espaços repletos de contradiçôes paisagísticas, que ao mesmo tempo, de forma mutualística combina elementos do arcaico e do moderno em uma síntese pitoresca, é a própria criação, imagem e semelhança do modo de produção capitalista. Suas ruas, avenidas, indústrias, lojas, bairros e pessoas em constante movimento, fazem da cidade um local da objetividade, do tempo escasso, dos dias curtos e de relaçóes frias. Assim como nos empreendimentos capitalistas, que exigem uma determinada racionalidade e a criação de determinados significantes objetivos - normas, leis, estatutos - a cidade também possui todo um sistema simbólico e imagético que introduz o indivíduo em uma racionalidade citadina.

Nesse sentido, Simmel ([1903] 2005) destaca que dentro do espaço de sociabilidade moderna, um dos problemas que afligem o ser humano é uma suposta pretensão em preservar elementos como autonomia e singularidade existencial numa sociedade superior em termos técnicos, históricos e culturais. Quase como se fosse uma quimera a devorar o homem, a modernidade infla os sujeitos a se comportarem de uma forma padrão, se desprendendo de si mesmos, buscando refúgios perante uma vida nervosa ocasionada por rápidas mudanças do mundo interior e exterior. A grande cidade 
moderna possui espaços topofílicos em que os indivíduos buscam fugas diante de uma vida racional, esquematizada e rotineira. Para Simmel ([1903] 2005) essa fuga e busca pelo paraíso perdido - tomando a licença para citarmos a monumental obra do poeta inglês John Milton - implicaria na perseguição por um paraíso para além da suplementação das necessidades materiais, representaria também uma forma de sociabilidade frente ao desprendimento de si, ocasionado pela racionalidade burocrática. Entretanto, como imagem e semelhança de um modo de vida capitalista, essa mesma cidade é o local da economia monetária, do constante fluxo de matéria e informação. E o local em que o homem se pauta pelo entendimento e em uma contabilidade moderna e em um sistema de signos, que oferece uma imagem de exatidáo da vida, de como ela deve ser.

Por esse ângulo, a burocracia e a racionalidade refletida por Weber ([1905] 2013) faz com que o indivíduo se torne um grão de areia em meio a uma organizaçáo monstruosa de coisas e potências que gradualmente subtrai os progressos, espiritualidades e valores. De modo semelhante à empresa capitalista, as pessoas passam a ter funçôes calculáveis; sendo reduzidas a peças de uma máquina racional maior que elas. Dentro desse foco, ao ligarmos empresa capitalista à racionalidade que permite um tipo de sociabilidade que deu origem ao capitalismo, observamos que na contemporaneidade esses elementos surgem com uma nova roupagem com o advento do neoliberalismo. Dessa forma, procuramos no tópico a seguir trazer a reflexão de dois sociólogos franceses: Pierre Dardot e Christian laval. Esses autores realizam importantes apontamentos sobre o tipo de racionalidade adotada pelo neoliberalismo, e os impactos que incidem sobre os sujeitos.

\section{UM DEBATE ACERCA DO NEOLIBERALISMO: UMA NOVA "RACIONALIDADE" DO SER?}

O termo Neoliberalismo se popularizou em meados da década de 1980 através das medidas econômicas e administrativas adotadas pela ex-primeira ministra da Inglaterra Margaret Thatcher (1925-2013) e pelo ex-presidente estadunidense Ronald Reagan (1911-2004). Um dos aspectos principais dessas duas administraçóes era o questionamento quanto ao papel da economia na promoção do Estado de bem-estar social. Como economias centrais no capitalismo, esses dois países em grande medida influenciaram o restante das naçóes ao redor do mundo. Esse movimento, associado com a derrubada do muro de Berlim em 1989 marcava uma clivagem importante na história contemporânea, uma vez que do ponto de vista material, a maior oposição ao modo de produção capitalista - o socialismo real, ou a Estado operário - desmoronava, dando a intelectualista burguesa à sensação de um "fim da história".

Além desses elementos históricos é muito comum associar o Neoliberalismo como sinônimo da desregulamentação financeira, abertura dos mercados e domínio do capital financeiro sobre o endividamento público. Contudo, para além desses elementos, que também fazem parte do Neoliberalismo, Dardot e Laval ([2009] 2017) refletem de forma crítica sobre o tema e nos presenteiam com algumas possibilidades de aprofundamento acerca do tema.

Segundo esses autores, o debate acerca do Neoliberalismo entre os economistas retoma uma ampla discussão sobre o papel a ser desempenhado pelo Estado junto à sociedade. Para além de uma instituiçáo que racionaliza políticas, o Estado tomado pelo Neoliberalismo seria um ente ativo na promoção da concorrência como nova forma de concepção das relaçóes sociais. Desse ponto de vista, o debate liberalismo e Neoliberalismo não estaria reduzido a intervenção do Estado na 
Economia, mas na própria materialização de uma forma societal de organizar a sociedade, conforme apontam os autores:

O neoliberalismo é um sistema de normas que hoje estão profundamente inscritas nas práticas governamentais, nas políticas institucionais, nos estilos gerenciais [...] esse sistema é tanto mais 'resiliente' quando excede em muito a esfera mercantil e financeira que reina o capital. Ele estende a lógica do mercado muito além das fronteiras estritas do mercado, em especial produzindo uma subjetividade 'contábil' pela criação da concorrência sistemática entre os indivíduos (DARDOT, LAVAL, [2009] 2017. p. 30).

Essa subjetividade contábil, diferentemente das observaçôes realizadas por Weber ([1917] 2014), possui como fonte de atuação o plano da concorrência. Em contraponto ao liberalismo clássico, o Neoliberalismo seria um fenômeno cujo fundamento residiria na promoção da concorrência, e não apenas na livre circulação mercadológica. Esse fator por si só permite evidenciar que muito longe de estarmos debatendo acerca do intervencionismo estatal, reflete-se aqui, o tipo de intervencionismo estatal e para quem.

Para além de uma ampliação e estímulo à concorrência, Dardot e Laval ([2009] 2017) salientam que ao surgir como crítica a doutrina do laissez faire, o Neoliberalismo alude um intervencionismo Estatal como forma de criar condições necessárias ao amplo desenvolvimento da concorrência em uma escala individual, social e institucional. Desse modo, os mecanismos Neoliberais estariam distantes de serem apenas de ordem econômica, possuiriam como essência a instauração de uma sociabilidade marcada pela concorrência até mesmo no nível do cotidiano. É desse modo que na Administraçáo pública, por exemplo, observa-se um movimento no final do século XX - náo coincidentemente com a ascensão dos governos de Thatcher e Reagan - a importação da lógica do mercado para o espaço administrativo público. Sob inspiração Neoliberal, surge um modo de gestão das relaçóes sociais de produção que é inteiramente instrumental, formal e focalizada no aumento da eficácia associada à redução de custos.

A empresa capitalista seria o tipo ideal na racionalidade empreendida pelo Neoliberalismo de um modelo de organização que deveria ser replicado às demais instâncias da sociedade. No Estado vemos a importaçáo dessa lógica por meio da instituição de regras concorrenciais do mercado para o setor público: mercadorização das instituiçóes públicas que passariam a funcionar de acordo com regras empresariais e a elevação da concorrência como instrumento mais eficiente na melhoria do desempenho da ação pública (DARDOT; LAVAL [2009] 2017). Ao se basear nesses princípios, a administração Thatcher, por exemplo, realizou uma série de reformas de cunho "gerencial" de modo a implantar a concorrência no setor público. Os serviços públicos passaram a funcionar com base em resultados a serem comparados. Segundo Dardot e Laval ([2009] 2017), essa reforma gerencial aparece de forma "neutra" sob a batuta da administração, o argumento utilizado é que o gerencialismo não possui lado político, o que explicaria sua adoção tanto por partidos da direita quanto da esquerda do espectro político.

Todavia, além de influenciar a organização estatal, essa racionalidade incide sobre a vida dos indivíduos. Estes passam a viver em um mundo caótico e esquizofrênico, sendo impulsionados a uma eterna competitividade que vai além das relaçóes do mercado. Conforme aponta Laval (2018), essa dinâmica se materializa nas relaçôes sociais mais banais: o desempenho sexual, por exemplo, é um desses elementos, que passa a ser medido, avaliado e comparado. A busca pelo sucesso e a necessidade do exibicionismo seriam elementos dessa instrumentalização da "objetividade empresarial 
da concorrência" na contemporaneidade. Esse sujeito concorrencial seria a nosso ver, uma dimensão ontológica que permite ao Neoliberalismo ser esse fenômeno que se metamorfoseia e se aplica da escala subjetiva a objetiva.

É nessa perspectiva que o Neoliberalismo se aplica às Administraçôes públicas dos Estadosnaçóes. Estes, além de incorporarem o paradigma concorrencial, precisam aplicar sobre suas próprias bases o tacão da concorrência em prol de uma melhor "oferta" de serviços públicos. No tópico a seguir poderemos observar como essa dinâmica se materializa na forma como os governos administram seus recursos públicos, dentro de uma lógica neoliberal supostamente neutra.

\section{A NEUTRALIDADE DO GERENCIALISMO NA ADMINISTRAÇÃO PÚBLICA}

Ao aparecer como uma doutrina "neutra", o Neoliberalismo aplicado a administração pública toma uma forma técnica gerencial, sendo amplamente utilizado como panaceia na resolução de todos os problemas. Tudo ou quase tudo é relacionado a problemas de gestão, eficiência, eficácia e governamentalidade. Embora o paradigma weberiano da dominaçáo racional legal tenha grande efeito sobre a forma como os governos conduzem açóes e meios de organizar e criar consenso na sociedade, o padrão neoliberal ressignifica essa lógica organizativa e passa a adotar um modelo dito como pós-weberiano baseado no governo Empresarial e na promoção da concorrência Dardot e Laval ([2009] 2017).

Sem nos desvincularmos da geopolítica mundial, é importante destacar o que representou o esgotamento do padrão de acumulação keynesiano de intervencionismo estatal em meados da década de 1970 e a ascensão de governos liberais nos Estados Unidos e Inglaterra em meados da década de 1980. Na América Latina com o crescimento do endividamento público e a crise de hegemonia em regimes ditatoriais - a exemplo do Brasil - e o retorno a democracia burguesa com ascensão de governos baseados nas administraçóes anglo-saxônicas, passamos a presenciar reformas estatais no sentido de superar o modelo burocrático de administração para instaurar uma maior flexibilidade.

Conforme aponta Andrews (2010) já no final da década de 1970 o Estado de bem-estar social é substituído na Europa por uma política de contenção orçamentária pautada em ideias de eficiência administrativa. Nos Estados Unidos também é implantada essa política com o objetivo de conter gastos sociais (mesmo que o déficit público daquele país continuasse a aumentar de forma exponencial como resultante dos gastos militares na corrida armamentista). Nesse sentido, como a empresa capitalista era considerada como modelo ideal de organização, surge na Administraçáo Pública o que comumente se denominou New Public Management; modelo pós-burocrático, ou como é conhecido no Brasil: Administração pública gerencial. De forma geral, as principais características dessa forma de organizar o setor público estão midiatizadas pela perspectiva concorrencial e mercadológica, sendo comum a importação de conceitos e práticas da esfera privada. - formas organizativas pautadas na concorrência, estímulo à competição; ampliação das forças do mercado; elaboração de indicadores de qualidade, etc. - na Administração estatal.

Segundo Laval (2018) há um elo entre subjetividade e neoliberalismo que implica em uma racionalidade neoliberal, seja no âmbito público ou privado, para esse autor ocorre um aprofundamento do utilitarismo e da perspectiva individualista na sociedade contemporânea. Essa concorrência não se consubstancia apenas entre empresas multinacionais, mas, sobretudo, no nível das próprias relaçôes interpessoais, nas famílias, na escola e no ambiente de trabalho. 
Não se trata de anarcocapitalismo e muito menos de uma não intervenção estatal, pelo contrário, o Estado nesse processo tem como papel criar as condiçóes necessárias à concorrência na esfera pública e privada como uma forma de garantir que os melhores vençam e que os recursos sejam mais bem alocados. Nesse sentido, através de uma forma que se apresenta como "neutra" e sem vinculação ideológica, o gerencialismo acaba por realizar a tarefa de ir minando as políticas sociais por dentro da própria estrutura Estatal. O público não teria espaço e muito menos "vocaçáo" para gerir os recursos produzidos pela própria sociedade. Homens e mulheres públicos deveriam ser expostos à concorrência, tendo em vista que suas escolhas são guiadas pelo interesse egoísta e utilitários. Sendo assim, não teria sentido em "blindar" as instituiçóes e os indivíduos da concorrência.

\section{CONSIDERAÇÕES FINAIS}

Dentro dos apontamentos que realizamos nesse artigo, gostaríamos de chamar atenção aos elementos da própria dinâmica subjetiva dos indivíduos frente ao paradigma neoliberal. Chama atenção como o elemento concorrencial se faz presente em nosso cotidiano. Se em um padrão burocrático os indivíduos precisavam seguir os estatutos, hoje, cada indivíduo deve criar e seguir seu próprio estatuto para o alcance um lugar ao sol. Sujeitos que náo se encaixam nessa perspectiva concorrencial sáo enxergados como fracassados e empecilhos que precisam de um maior enquadramento a lógica competitiva. Conforme apontamos, ao criar as condiçóes para esse tipo de sociabilidade, o Estado acaba aplicando a si mesmo essa conduta e adota uma visão empresarial com o trato da coisa pública. Ademais, as empresas capitalistas são vistas como modelos a serem seguidos, devido ao seu "alto grau" de eficiência e qualidade. Consideramos essa visão altamente ideológica e portadora de uma neutralidade teatral, cuja performance reduz os problemas da sociedade ao elemento da gestáo e do gerenciamento dos recursos produzidos socialmente de forma técnica.

Esse reducionismo não considera as estruturas de classes existentes, as disputas pelos recursos públicos, os interesses que estão além de um utilitarismo individual. Não pensar nesses elementos e implantar toda uma estrutura técnica como panaceia para a promoção de uma maior efetividade das açôes públicas implica em reproduzir formas de dominação capitalista sob uma roupagem técnica e instrumental. Com isso, não afirmamos que os recursos sociais devam ser desperdiçados ou, que não deva existir um controle, o que pontuamos em nossa reflexão é que tipo de controle, para quem e como ele é realizado. A partir da nossa reflexão, lançamos como hipótese que o gerencialismo tem por função obscurecer a verdadeira tensionalidade existente na luta de classes moderna. Sob uma suposta cientificidade redentora dos desperdícios, todo o aparato intelectual é redimensionado a uma grande empresa capitalista, sem vínculo factível com a realidade, sem questionar as contradiçóes, por exemplo, de um Estado neoliberal que ao estimular a concorrência, continua alimentando o capital portador de juros de forma crescente (SANTANA, 2018).

Sendo assim, como desdobramento dos elementos por nós levantados no presente artigo, constatamos a necessidade de um olhar empírico acerca das políticas públicas que fazem uso do gerencialismo no redimensionamento de suas açóes e em pesquisas sociológicas que desvelem essa relação em um nível subjetivo. A intenção dessa agenda de pesquisa reflete a preocupaçáo de observar de que forma a sociologia pode contribuir para esse debate, respondendo assim a lacunas de pesquisas existentes em um âmbito nacional. 


\section{REFERÊNCIAS}

ANDREWS, Christina Windsor. Da década perdida à reforma gerencial: 1980 - 1988. In: ANDREWS, Christina Windsor; BARIANI, Edison (Org.). Administraçáo pública no Brasil: breve história política. São Paulo: Editora Unifesp, 2010. pp.85 - 118.

DARDOT, Pierre; LAVAL, Christian. A nova razáo do mundo: ensaio sobre a sociedade neoliberal. São Paulo: Boitempo, [2009] 2017.

MARX, Karl. Prefácio de Marx ao livro Contribuição à crítica da economia política. In.: DANTAS, Gilson; TONELO, Iuri. O método em Karl Marx. São Paulo: ISKRA, [1859] 2016, p. 37 - 42.

MATTOS, Laura Valladão de. As razões do laissez-faire: uma análise do ataque ao mercantilismo e da defesa da liberdade econômica na Riqueza das Naçóes. Rev. Econ. Polit. [online]. 2007, vol.27, n.1, pp.108-129. ISSN 0101-3157.

PIERUCCI, Antônio Flávio Pierucci. Max Weber. Universidade Virtual do Estado de São Paulo - UNIVESP [São Paulo], 04 fev. 2016. (28 min) Disponível em:https://www.youtube.com/watch?v=wDEVx65oa3s. Acesso em: 10 Dez. 2018.

SANTANA, Laudicéia Araújo. Transformismo e o sistema da dívida pública brasileira nas definiçóes programáticas do Partido dos Trabalhadores e no Governo Lula (2003 - 2010). Tese de Doutorado. Universidade Federal de Campina Grande. Centro de Humanidades: Programa de Pós-Graduaçáo em Ciências Sociais. Campina Grande, PB, 2018.

SIMMEL, Georg. As grandes cidades e a vida do espírito (1903). Mana. Rio de Janeiro , v. 11, n. 2, p. 577-591, Out. 2005 . Disponível em: http://www.scielo.br/scielo.php?script=sci_arttext\&pid=S0104-93132005000200010\&lng=en\&nrm=iso >. Acesso em: 21 Dez. 2018.

WEBER, Max. Parlamento e governo na Alemanha reorganizada: sobre a crítica política do funcionalismo e do partidarismo. In.: Escritos políticos. São Paulo: Martins Fontes, [1917] 2014, pp. 167 - 227.

WEBER, Max. A ética protestante e o espírito capitalista. São Paulo: Martin Claret, [1905] 2013. 301p.

WEBER, Max. O que é a burocracia. Brasília: Conselho Federal de Administração. 2014. 